\title{
The Implications of Soaring Gas and Coal Prices on Europe's Energy Poverty Trap
}

Fateh Belaïd

\section{Instant Insight}




\section{About KAPSARC}

The King Abdullah Petroleum Studies and Research Center (KAPSARC) is a non-profit global institution dedicated to independent research into energy economics, policy, technology and the environment across all types of energy. KAPSARC's mandate is to advance the understanding of energy challenges and opportunities facing the world today and tomorrow, through unbiased, independent, and high-caliber research for the benefit of society. KAPSARC is located in Riyadh, Saudi Arabia.

\section{Legal Notice}

(C) Copyright 2021 King Abdullah Petroleum Studies and Research Center ("KAPSARC"). This Document (and any information, data or materials contained therein) (the "Document") shall not be used without the proper attribution to KAPSARC. The Document shall not be reproduced, in whole or in part, without the written permission of KAPSARC. KAPSARC makes no warranty, representation or undertaking whether expressed or implied, nor does it assume any legal liability, whether direct or indirect, or responsibility for the accuracy, completeness, or usefulness of any information that is contained in the Document. Nothing in the Document constitutes or shall be implied to constitute advice, recommendation or option. The views and opinions expressed in this publication are those of the authors and do not necessarily reflect the official views or position of KAPSARC. 
With the recovery of the world economy following the easing of restrictions designed to contain COVID-19, energy demand has surged even as natural gas stocks were dangerously low. This triggered one of the first significant energy shocks of the green era and exposed the fragilities of the ongoing process to green the energy system. A recent CNN article indicates that 80 million European households are struggling to stay warm, and the recent spike in energy costs will further aggravate this problem (CNN 2021). Here we examine the impact of booming energy prices on energy poverty in Europe. The analysis highlights how energy prices and the green transition may exacerbate Europe's energy poverty trap. It emphasizes one of the negative effects of poorly designed climate policies. This discussion has important policy implications and triggers a debate on energy poverty in developing countries. It also constitutes a strategic information vector for understanding the energy poverty phenomenon and implementing future energy policies and programs to reduce inequalities in developing countries.

\section{Energy poverty definition, the conceptualization of factors causing energy poverty, and its socioeconomic impacts}

In recent years, rising energy and housing costs for poor households have fueled public debate regarding energy poverty. Reliable access to energy services is crucial for reducing various forms of poverty and sustainable economic growth. After the economic ravages of COVID-19, low-income countries are experiencing a more acute and long-lasting downturn, which has increased poverty around the world and reversed recent trends of reduced inequality. According to World Bank estimations, between 88 and 115 million people fell into extreme poverty in 2020, and this figure will reach between 119 and 124 million in 2021 (World Bank 2020). Without the outbreak of the pandemic, it is expected that the poverty rate would have fallen to $7.9 \%$ in 2020 . In combination with the spiking gas prices, this could exacerbate the longstanding energy poverty issue, which stems from a combination of low household incomes, high energy costs, and energy-inefficient housing.

Energy poverty is an umbrella term used to denote households' inability to obtain sufficient energy for essential services such as cooking, heating, cooling, and household lighting (Belaïd 2018). Energy poverty - which is conceptualized as a household's inability to meet its primary energy needs - is a pervasive concern in developed countries and elsewhere (Boardman 2009). Different concepts have been used in the literature to apprehend similar circumstances that entail both affordable and reliable access to energy sources, including energy vulnerability, and energy poverty (Bouzarovski 2014). Despite the necessity of energy services for individual well-being (e.g., cooking, cooling, heating, and lighting), policymakers struggle to identify the extent and scope of energy poverty even in developing economies.

The conceptualization of the critical factors driving energy poverty, and the number of cycles in which the vulnerable could be trapped, is illustrated in Figure 1. 
Figure 1. Conceptualization of factors causing energy poverty and its socioeconomic impacts.

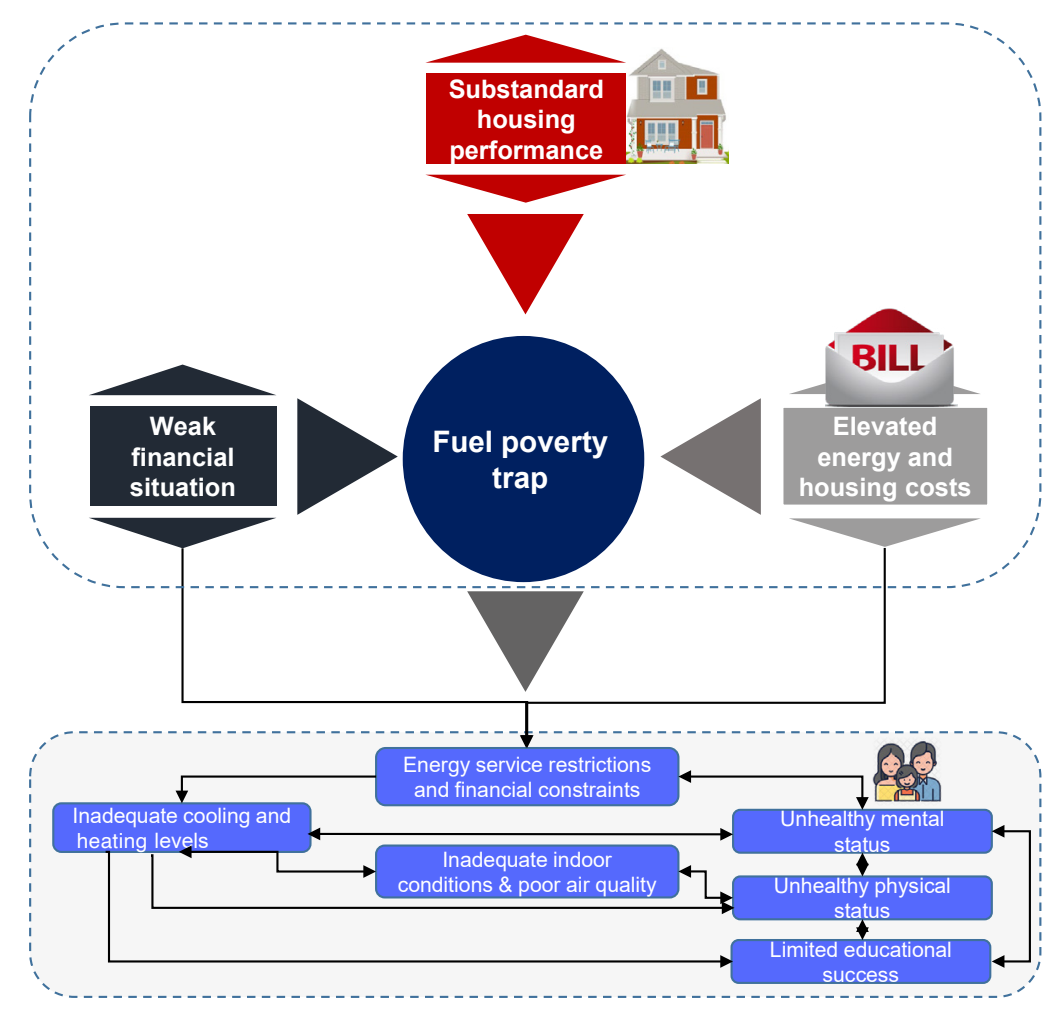

Source: Author

Determining energy poverty and assessing its impact on humans' health and well-being is a rising social issue worldwide (Llorca et al. 2020). Understanding the extent of energy poverty is critical for several reasons, including enhancing people's mental and physical health in low energy-efficient housing (Hernández 2016; Kearns et al. 2019), gaining an in-depth appreciation and understanding of the energy efficiency of the housing stock (Belaïd et al. 2020, 2021), and improving environmental quality (Boardman 2013; Belaid 2019). Increasing housing and energy costs cause financial stress and societal issues. Unaffordability impedes children's education and employment prospects, delays marriages, reduces fertility and constrains mobility (Galster and Lee 2021).

Energy poverty is now recognized as a distinct form of inequality (Galvin and Sunikka-Blank 2018; Burlinson et al. 2018). Its adverse impact on household conditions has led to it being a significant focus of policy and academic debate. An important strand of research has been the measurement of the extent of energy poverty, along with its fundamental determinants. There is considerable agreement among economists about the imperative to address energy vulnerability and cold home-related negative health impacts as a route to improving the quality of life of many households by making their homes warmer and more efficient. This should lead to a substantial reduction in health inequality, as well as making an essential contribution to tackling residential greenhouse emissions (Boardman 2013; Poruschi et al. 2018). Within this 
context, United Nations Sustainable Goal 7 (SDG 7) is designed to guarantee universal access to reliable, affordable, sustainable, and contemporary energy by 2030. It also incorporates efforts to eliminate energy poverty with climate change action through goals to enhance the global use of renewable and efficient energy.

\section{Impact of the current boom in energy prices on European energy poverty}

The world's population has nearly doubled from 3.8 billion to 7.7 billion between 1972 and 2019. During the same period, annual per capita energy demand also increased from 57 to 75.7 gigajoules (GJ) (Belaïd and Al-Dubyan 2021). Urbanization has accelerated globally, and intensive energy use already presents serious challenges to society, including environmental quality degradation, increasing socioeconomic inequalities, energy insecurity, intensive energy use, and increased natural and man-made disasters. As the global energy market undergoes a rapidly accelerating transition, driven by a range of factors, there have been unprecedented energy price surges. There are many factors driving investment patterns, including technological changes, shifting consumer preferences, and policy measures. Tackling climate change is a key consideration of the energy transition, but policymakers are also focused on other competing priorities, including enhancing energy security, ensuring affordable energy supplies, and providing universal access to energy.

The current supply crunch in the energy market, one of the first in this transition to greener energy, shows the vulnerability and the underlying difficulties of the energy transition. The primary origin of this crisis is the rebound in energy demand amid a post-pandemic economic recovery. Global coal and natural gas prices have risen to record levels in recent weeks, and Brent Crude prices have climbed more modestly to over $\$ 85.5$ per barrel. $^{1}$

These price rises are not due to a shortage of crude oil or refined products, they are due to the recent economic rebound, with electricity demand from the manufacturing industry leading to global supply shortages. In Europe, myriad factors are behind the surge in prices, including tensions prevailing in the gas market, the expectation of a tighter gas supply, increasing heating energy demand, poor energy market design, and weak wind speeds, leading to a drop in wind power generation. In addition to the reduced investment in gas infrastructure and its maintenance since the COVID-19 pandemic, the situation has been exacerbated by the political differences between Russia and Europe. They have not yet reached an agreement to increase gas supplies from Russia to Europe, as Russia would like long-term contracts and Europe would prefer to contract via the spot market.

Currently, Europe is experiencing unprecedented high energy prices that could derail the post-pandemic economic recovery, strain household incomes, and even slow the nascent ecological transition (e.g., the average day-ahead electricity price for Central European countries reached 170 euros per megawatthour on September 15, more than doubling between June and September). 
These high energy prices may spill over into the longstanding energy poverty phenomenon tied to elevated energy costs, low incomes, and energy-inefficient housing. Coupled with the economic burden caused by the COVID-19 outbreak, households in countries such as Italy, Spain, Poland, and France are facing higher energy bills than ever before.

Prior to the pandemic, estimates indicated that 57 million people in Europe suffered from cold homes in the winter, 104 million could not keep their houses cool during summer, and 52 million could not pay their energy bills or faced delays in paying them. ${ }^{2}$

Recent findings show that the adverse effects of the pandemic on energy poverty levels in Europe will be reversed very slowly, not before 2025 . There will certainly be significant differences in energy poverty levels between countries, deepening the gap between countries with low levels of energy poverty and those with high levels of energy poverty (Carfora et al. 2021).

The current spike in energy prices, combined with the economic disruption resulting from the COVID-19 pandemic, has exacerbated pre-existing inequalities, including energy poverty (Belaïd et al. 2021). This situation exposes even more households to the risk of being disconnected from gas and electricity networks due to their inability to pay their bills.

\section{Insights into energy poverty in developing countries}

Reliable and affordable access to energy is essential for poverty reduction and sustainable development in every country. The availability of affordable, reliable, and sustainable energy is essential to sustain well-being, which is also a prerequisite for the achievement of SDG 7 and certain other SDGs.

There is a growing awareness in developed countries of the impact of low incomes, low energy performance housing, and rising energy costs on people's ability to access a basic level of energy service and stay comfortable in their homes, and several institutions (e.g., the European Commission) have designated it a political priority. However, studies on energy poverty in developing countries are still limited.

This analysis substantiates the idea that reforming the energy market and enhancing domestic power service supply in developing countries needs efficient and proactive policies that supplement the ongoing energy transition and electricity tariff reform processes. These policies could include both supply-side actions, such as optimizing electricity service costs, and demand-side strategies geared toward large consumers who may have an increased willingness to pay for reliable electricity supplies. 
Moreover, emphasis should be placed on establishing a dedicated energy poverty entity with a specific mandate to assess, monitor, and improve expertise on energy poverty at the national or regional level. This will help provide guidance for policymakers and help accelerate the ongoing energy transition. In addition, by offering data and shared resources, it will support informed decision-making at national, local, and regional levels.

Besides helping to gain a comprehensive overview of the scope of the energy poverty phenomenon, such an institution may also act as a vector to stimulate public engagement and disseminate information and best practices among public and private stakeholders.

\section{Conclusions}

This insight presents an initial analysis of the issues surrounding energy poverty. It is intended to foster a policy debate on the current challenges of the energy transition and climate change mitigation.

Much remains to be understood regarding the prevalence of energy poverty and its impact on well-being and inequality both in developed and developing countries. Current developments in Europe justify and will raise the interest in more studies that examine and identify the socioeconomic effects of energy-vulnerable households. The ultimate goal is to design relevant policy measures to protect people in vulnerable situations.

In particular, it is crucial to investigate the perceptions of those in energy poverty regarding the leading causes of their situation, including their inability to achieve a good energy efficiency level, energy costs, and their lack of income to pay for energy bills. It will also be interesting to investigate the capacity and the energy poor's willingness to pay to improve their housing energy performance according to their income level and the energy performance they would expect. Another valuable question to investigate is whether housing improvements effectively ameliorate the 'lived experience' of energy poverty.

Other questions that could be addressed include what strategies individuals adopt to cope with energy poverty. The most promising dimension to explore is the economic strategies employed by households to balance their material hardship with energy needs. Finally, beyond the financial aspects, a valuable topic for future research is the examination of households' behavioral responses to energy energy poverty, i.e., how households cope with consuming less energy.

\section{Endnotes}

${ }^{1}$ https://seekingalpha.com/news/3756848-supply-crunch-pushes-crude-oil-to-record-ninth-straight-weeklygain

${ }^{2}$ https://www.eumayors.eu/support/energy-poverty.html 


\section{References}

Belaïd, Fateh, Adel Ben Youssef, and Nathalie Lazaric. 2020. "Scrutinizing the direct rebound effect for French households using quantile regression and data from an original survey." Ecological Economics 176: 106755. https://doi.org/10.1016/j.ecolecon.2020.106755

Belaïd, Fateh, and Mohammad Al-Dubyan. 2021. "The Role of Residential Energy Efficiency in Shaping the Energy Transition in Saudi Arabia: Key challenges and initiatives." IAEE Energy Forum. Fourth Quarter 2021: 19-23. https://www.iaee.org/en/publications/newsletterdl.aspx?id=970

Belaïd, Fateh, Véronique Flambard, and Michelle Mongo. 2021. "How large is the extent of COVID-19 on territorial inequality? France's current situation and prospects." Applied Economics: 1-17. https://doi.org/10.10 80/00036846.2021.1976389

Belaïd, Fateh, Zeinab Ranjbar, and Camille Massié. 2021. "Exploring the cost-effectiveness of energy efficiency implementation measures in the residential sector." Energy Policy 150: 112122. https://doi. org/10.1016/j.enpol.2020.112122

Belaïd, Fateh. 2018. "Exposure and risk to fuel poverty in France: Examining the extent of the fuel precariousness and its salient determinants." Energy Policy 114: 189-200. https://doi.org/10.1016/j. enpol.2017.12.005

Belaïd, Fateh. 2019 "Role of economy and income to fall in energy poverty: Policy act." In Urban Fuel Poverty, pp. 17-40. Academic Press. https://doi.org/10.1016/B978-0-12-816952-0.00002-8

Boardman, Brenda. 2013. Fixing fuel poverty: Challenges and Solutions. Routledge. https://www.routledge. com/Fixing-Fuel-Poverty-Challenges-and-Solutions/Boardman/p/book/9781844077441

Bouzarovski, Stefan. 2014. "Energy poverty in the European Union: Landscapes of vulnerability." Wiley Interdisciplinary Reviews: Energy and Environment 3, no. 3: 276-289. https://doi.org/10.1002/wene.89

Burlinson, Andrew, Monica Giulietti, and Giuliana Battisti. 2018. "The elephant in the energy room: Establishing the nexus between housing poverty and fuel poverty." Energy Economics 72: 135-144. https:// doi.org/10.1016/j.eneco.2018.03.036

Carfora, Alfonso, Giuseppe Scandurra, and Antonio Thomas. 2021. "Forecasting the COVID-19 effects on energy poverty across EU member states." Energy Policy: 112597. https://doi.org/10.1016/j. enpol.2021.112597

CNN. 2021. "80 million European households struggle to stay warm. Rising energy costs will make the problem worse." September 30. https://edition.cnn.com/2021/09/30/business/europe-energy-poverty/index. html 
Galvin, Ray, and Minna Sunikka-Blank. 2018. "Economic inequality and household energy consumption in high-income countries: A challenge for social science based energy research." Ecological Economics 153:78-88. https://doi.org/10.1016/j.ecolecon.2018.07.003

Hernández, Diana. 2016. "Understanding 'energy insecurity' and why it matters to health." Social Science \& Medicine 167:1-10. https://doi.org/10.1016/j.socscimed.2016.08.029

Kearns, Ade, Elise Whitley, and Angela Curl. 2019. "Occupant behaviour as a fourth driver of fuel poverty (aka warmth \& energy deprivation)." Energy Policy 129: 1143-1155. https://doi.org/10.1016/j. enpol.2019.03.023

Llorca, Manuel, Ana Rodriguez-Alvarez, and Tooraj Jamasb. 2020. "Objective vs. subjective fuel poverty and self-assessed health.” Energy Economics 87: 104736. https://doi.org/10.1016/j.eneco.2020.104736

World Bank, 2020. Global Economic Prospects 2020. World Bank Publications, Washington DC, ISBN 9781-4648-1580-5. https://doi.org/10.1596/978-1-4648-1553-9 


\section{JKAPSARC}

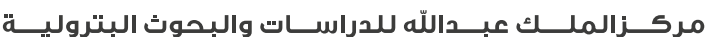

King Abdullah Petroleum Studies and Research Center

www.kapsarc.org 